\title{
Mapping the Way Forward: Education for Sustainability in Architecture and Urban Design
}

\author{
Sergio Altomonte, Peter Rutherford and Robin Wilson \\ Department of Architecture and Built Environment \\ University of Nottingham, United Kingdom
}

\section{ABSTRACT}

Given the growing relevance of the sustainability agenda to the professions of the built environment, one way to ensure that its mandates are effectively integrated in architecture and urban design is to revisit the role that education, particularly at University level, can play. It is well understood that this requires a significant paradigm shift in the underlying pedagogies involved in educating for sustainability. It could be argued therefore that one of the main challenges is to address the dichotomy between effectively integrating creative expression with rigorous technical exploration, this being a core demand of high quality sustainable design. As such, advances in curriculum development must seek to promote this integration more effectively, and, in so doing, facilitate knowledge transfer between both the creative and scientific disciplines that are core to a sustainable architecture and urban design process. In response, this paper explores the outcomes of a European project, EDUCATE (Environmental Design in University Curricula and Architectural Training in Europe), seeking to look critically at the barriers and opportunities afforded by implementing sustainability in pre- and post- professional education in architecture and urban design, and exploring some of the strategies required to promote such integration.

Keywords: Sustainability, Education, Curriculum, Architecture, Urban Design, Knowledge Transfer

Received 1 December 2011; Revised 24 March 2012; Accepted 27 August 2012 


\section{Introduction}

Education for sustainability in the built environment is an incumbent imperative. All construction professionals have an obligation to ensure that the buildings and urban spaces that flow from the design process are a product of careful and responsible practice. This has not always been the case and, rightfully, the finger has in part been pointed at academia for not providing the education that would help such professionals respond to contemporary sustainability challenges.

Indeed, there has been significant response from many quarters claiming that major changes are required to the ways that new generations of architects and engineers are taught within academic institutions at pre-and post-professional level (HEA, 2005).

Several issues stand in the way of progressing from reductionist and/or deterministic teaching approaches to those that are more inclusive, integrated and systems-thinking based (UNESCO, 2009). One such issue surrounds the definition ascribed to, or the scope surrounding, the amorphous concept of 'sustainability'. This term has been interpreted in numerous ways and, especially when associated with the agenda of education in disciplines of the built environment, has often failed to be ascribed a precise meaning. Debates surrounding social and cultural sustainability have at times overshadowed energy and resource conservation or vice-versa. Indeed, one could argue that the rather generalist nature of many built environment programmes is in itself unhelpful, and questions or de-prioritises the fundamental ethos behind sustainable design (EDUCATE, 2010a).

These issues can be compounded where the education process sits within, and needs to respond to, legislation, professional qualification criteria and accreditation frameworks that themselves fail to explicitly place sustainability at the core of curricula. In some ways, this is not necessarily negative, as sustainable design within the context of the built environment must cover many important issues. One could argue that a highly reductionist pedagogy that concentrates exclusively on energy use and resource conservation, for example, does not embrace, or expose students to, many other highly 
significant and interrelated issues such as those surrounding human activity, socio-cultural, economic, political or other environment-related issues.

This presents a dilemma to educators, whereby providing sufficient breadth of coverage of what are considered important topics, often with complex interrelationships, is not always feasible within what is an already busy curriculum. However, it is undeniable that buildings themselves contribute significantly not only to climate change, but also to the health, well-being, comfort and satisfaction of those who occupy or experience them. In response, there is a strong argument that curricula must be developed carefully to ensure that these most pressing challenges are addressed as a priority.

Due to the broad nature of education in architecture and urban design - encompassing at once environmental, socio-cultural and economic issues - the ability to work through the complex requirements of sustainability is particularly relevant, although the challenge is such that it is often met with mixed success. This is due in part to the fact that there is a demand to look beyond the mere content of the curriculum, and grapple with the need to integrate sustainability in a manner that informs the discourse taking place within the building design process itself. As such, questions have to be asked about curricula employing rote and surface learning techniques that have been proven to exacerbate the divide between knowledge acquisition and the understanding that flows from its critical and reflective application. It is argued here that curricula should seek to bridge this divide and develop pedagogies that combine both technical and holistic issues of sustainability with a design approach that is inventive, creative and responsive to pressing environmental needs.

In response to these challenges, the EDUCATE project (Environmental Design in University Curricula and Architectural Training in Europe) - coordinated by the authors - was funded in 2009 by the European Commission's Executive Agency for Competitiveness and Innovation under the Intelligent Energy Europe programme. Building on a transnational overview of higher education and legislative frameworks, the project was set to promote the integration of sustainability in the 
teaching and practice of architecture and urban design, offering guidelines and underlying support to curriculum development at pre- and post-professional level (EDUCATE, 2011).

This paper aims to present and critically analyze some of the outcomes of the EDUCATE project. It explores barriers to the effective integration of sustainability in the education of architecture and urban design and, in response, discusses the opportunities that advances in pedagogy may bring to facilitate its implementation. In pursuit of these aims, the paper is structured in three parts: the first presents the challenges to the practice of sustainable design in the built environment; the second critically analyses the context of higher education and comments on the barriers and opportunities for promoting sustainability in teaching and learning; the third maps the way forward to the sustainable education of architecture and urban design students.

\section{Sustainability in the Practice of the Built Environment}

Awareness that buildings account for almost half of global energy consumption is placing significant demands on practitioners of the built environment (IPCC, 2007). Despite the fact that many professional firms would declare sustainability as a key element of their design approach, relatively few contemporary buildings have lived up to these claims. Conversely, there is a growing legacy of buildings that lack coherent sustainability measures and therefore have the potential for imposing ongoing negative impacts on the environment. Those designed along deterministic and 'energy-centric' lines, without paying heed to the numerous interrelated issues that go into their effective use and operation - or indeed the delight they bring to those experiencing them - while well intentioned, may in the end fare little better. This approach is not universal, however, and it is important not to detract from the many practices that embrace sustainability as core to their ethos and deliver buildings that succeed on all fronts (Clegg, 2007).

An early task in the EDUCATE project was to canvas views from those working within the built environment professions, relating specifically to how sustainability is perceived and explored within 
contemporary design practice and to the measures required to meet future challenges. Performed in collaboration with prescription and accreditation bodies worldwide, around 400 online surveys were collated from some 40 different countries (EDUCATE, 2010b). The results were analysed using simple statistical metrics, with the aim of exploring the main challenges associated with the implementation or integration of sustainability in the built environment. The surveys were also designed to explore market demands and expectations with respect to the competencies sought from students, thereby helping to understand the core skills that should be developed within higher education. The intention here of course was to inform a process designed to ensure that University curricula deliver graduates with the abilities needed to work within a highly competitive, demanding, and dynamically changing, profession.

\section{A Survey of the Key Stakeholders}

The survey was divided into three main sections, where practitioners were presented with a series of statements to which they had to express their views, respectively addressing sustainability in relation to: academic curricula; continuing professional development; and, regulations and clients' requirements. A further section of the survey gave respondents the opportunity to freely comment on their perception of the main challenges that affect the implementation of sustainability in professional practice. Table 1 below summarises the responses to some of the statements proposed by the survey (EDUCATE. 2010b).

\begin{tabular}{|l|c|c|c|c|c|c|}
\hline Proposed Statement & $\begin{array}{c}\text { Strongly } \\
\text { Agree }\end{array}$ & Agree & Neutral & Disagree & $\begin{array}{c}\text { Strongly } \\
\text { Disagree }\end{array}$ & NA \\
\hline $\begin{array}{l}\text { Sustainable design represents a core part of } \\
\text { the design approach of your practice }\end{array}$ & $47.3 \%$ & $40.8 \%$ & $6.8 \%$ & $4.6 \%$ & $0.5 \%$ & $0.0 \%$ \\
\hline $\begin{array}{l}\text { Sustainable design provides a creative input } \\
\text { and inspiration to your work }\end{array}$ & $43.5 \%$ & $41.4 \%$ & $9.7 \%$ & $4.3 \%$ & $1.1 \%$ & $0.0 \%$ \\
\hline $\begin{array}{l}\text { Sustainable design should be included in the } \\
\text { curricula of architectural education }\end{array}$ & $70.5 \%$ & $25.9 \%$ & $2.4 \%$ & $0.3 \%$ & $0.5 \%$ & $0.3 \%$ \\
\hline Competence in sustainable design should be & $38.9 \%$ & $33.0 \%$ & $13.2 \%$ & $10.5 \%$ & $3.5 \%$ & $0.8 \%$ \\
\hline
\end{tabular}




\begin{tabular}{|l|c|c|c|c|c|c|}
\hline required for professional registration & & & & & & \\
\hline $\begin{array}{l}\text { Is it important that professional bodies } \\
\text { organise courses in sustainable design }\end{array}$ & $50.3 \%$ & $36.5 \%$ & $9.7 \%$ & $1.6 \%$ & $1.1 \%$ & $0.8 \%$ \\
\hline $\begin{array}{l}\text { Regulations in your country adequately } \\
\text { support the practice of sustainable design }\end{array}$ & $4.9 \%$ & $30.0 \%$ & $22.4 \%$ & $30.3 \%$ & $12.4 \%$ & $0.0 \%$ \\
\hline $\begin{array}{l}\text { Your clients regard sustainability as an } \\
\text { opportunity beyond legislative requirements }\end{array}$ & $9.2 \%$ & $37.3 \%$ & $26.5 \%$ & $18.4 \%$ & $5.7 \%$ & $3.0 \%$ \\
\hline
\end{tabular}

Table 1. Selected responses to the survey

An overview of the results confirms that, at a global level, there is growing awareness and interest in the themes of sustainability, as well as an acceptance that it offers the potential to serve as a source of creative inspiration to the design process. A view that was broadly held within the openended comments, however, is that existing educational programmes do not yet fully support the promotion of sustainable design, suggesting significant room for improvement. Inadequate regulatory frameworks also influence the way in which sustainability is embraced by the various actors of the building industry. Indeed, the perception of the professional market is that client demands are all too often driven by aesthetic appearance, reductions in up-front investment and minimisation of operational costs, rather than by an overarching and ethical commitment to sustainable design. Basing on the survey, the idea that sustainable solutions are more expensive, or can stifle good design, is still prevalent among the various stakeholders of the construction sector.

When taken in the round, therefore, the combined results from the survey indicate a clear requirement to develop a framework for educating students and practitioners of the built environment that caters for the needs of both those working towards entry to the profession and those within it. Acknowledging that the role of the designer necessarily involves significant interaction with cognate professions and client bodies, there is significant value to be obtained in complementary measures that prepare the ground for a working environment where all players share awareness of the benefits of designing within the context of sustainability. 


\section{Barriers and Opportunities for Sustainable Design of the Built Environment}

In summary, a critical analysis of the results of the survey reveals that realising the potential that an informed response to sustainability offers as a design driver still faces a number of barriers:

\section{Regulations/Standards:}

- Lack of a legislative framework that creates real drivers and demands.

- Need for clearer standards, whose application is more strictly verified.

- Lack of a long-term vision and financial incentives to promote innovation in design.

\section{Knowledge/Education:}

- Insufficient training for architects, builders, consultants and policy-makers.

- Lack of multidisciplinarity and knowledge transfer between professional domains.

- Cultural norms that ignore the possibilities offered by sustainability, which is still considered as complex, expensive and lying within the domain of the specialist.

- Misleading claims and conflicting information on performance (e.g., 'greenwash').

- Misconceptions on costs, prejudices and mindsets that prioritise saving money at the time of investment rather than looking at costs of ownership.

In terms of regulations and standards, there is still work to be done on the part of policy-makers and bodies regulating access to the profession. In particular, there is a need to provide a legislative framework that effectively encourages and supports sustainable and inspirational design rather than merely imposing benchmarks to be satisfied. Conversely, current qualification and accreditation criteria established by professional institutions are often too inhomogeneous and characterised by loose requirements, especially those quantifying acquisition of the creative and technical skills that graduates are required to adopt within a responsible approach to sustainable practice. Finding the right balance between embracing a rigorous legislation and avoiding an excessively prescriptive regulatory environment is a challenge that needs to be met to ensure that the competence of practitioners is appropriate with respect to both creative design and technical knowledge, as well as 
the ethical formation necessary to practice in an industry that will increasingly demand a sustainable approach to design.

To accelerate the holistic implementation of sustainability in shaping the design of the built environment, it is desirable to promote education programmes that provide the multidisciplinary competence - supported by evidence and research-based knowledge - necessary to blend technical ability with the broader set of design skills brought to bear on creative problem solving.

Fulfilling this mandate requires significant reflection on the educational process that serves the needs of the building market. Since Universities make a significant contribution to the flow of new professionals joining the industry, it makes sense that this reflection starts with the curricula followed by students and the relationship between academic programmes and the aspirations of accrediting bodies. Given the importance of Continuing Professional Development (CPD) in maintaining the skill sets of building practitioners, there is also a compelling case to explore the ongoing education of professionals and how this is positioned relative to undergraduate provision. In terms of curriculum development, it is hence essential that, within the disciplines of architecture and urban design, sustainability is considered not as a mere box to tick in terms of energy efficiency or resource conservation. Rather, it requires a complex and overarching multidisciplinary approach that flows from commitment and expertise, offering the prospect to yield inspired architecture. Successful transition from student to a responsible practitioner necessitates that knowledge, skills and competence of sustainability are promoted through academic curricula, exposing students to the multifaceted challenges, as well as the opportunities, offered by sustainable design.

\section{Sustainable Design in Programmes of Higher Education}

Despite the challenges highlighted by the building industry regarding education for sustainability at academic and professional level, a global review of curricula in architecture and urban design 
indicates that the 'sustainable agenda' is beginning to assume a central position within higher education programmes (EDUCATE, 2010a).

Historically, core issues particularly surrounding environmental sustainability, such as energy use and conservation, were of specialist concern and seen to be within the domain of the building services or mechanical engineer. However, the recent return to a more passive and climateresponsive (bioclimatic) philosophy of design - where the building operates in concert with the prevailing climate, its occupants and its programme - has meant that sustainability is now a core concern within the disciplines of architecture and urban design, forming part of an overarching approach that must be considered from the inception of a project through to its completion. Unfortunately, curricula have responded slowly to this change in focus from a specialist to a more generalist domain, and therefore, from a pedagogical perspective, in many cases there still is inconsistency in the ways that sustainability has embedded itself within programmes.

Indeed, many academic institutions still make a program split between theoretical and applied teachings(EDUCATE, 2010a). During lectures, students are introduced to the fundamental principles, concepts and bodies of knowledge that - it is assumed - will then guide and inform design development within studio projects. Such teachings may centre on building physics - e.g., science of heat transfer, acoustics or lighting; these being contained either within core modules or, alarmingly, offered as elective-based modules - or socio-cultural considerations and economic analysis. A common feature of such approaches, however, is that the presentation of the core material is often completely alienated from its exploration within design.

As such, students are seldom able to fully engage with an integrated process that creatively investigates the implementation of sustainability in design practice (Altomonte, 2009). In addition, students are often expected to embark on design tasks with limited knowledge of the design process itself and often without having formed the basis of the conceptual framework within which solutions would be formulated. The knowledge and preconceptions that they bring to the design are 
frequently belittled or ignored, with modest attempt made at explaining why these may be misinformed (Rutherford and Wilson, 2006). Hence, the divide between the application of scientific knowledge (or knowledge that pertains directly to sustainability) and its realisation within the creative design process is perpetuated (Kock et al., 2002).

Such misconceptions are frequently exacerbated by a naive conception of the process of knowledge acquisition, recall and application. As a matter of fact, following a transmissive model of education that derives its methodologies from the epistemological assumptions of Positivism and technical rationality (Kincheloe, 2008), the approach to teaching the technical aspects of architecture and urban design generally succeeds in developing students who are merely "good problem solvers through the knowledge of mathematics and physical science" (Kirk and Mulligan 1996). Lectures are structured linearly, taking students step-by-step through processes and techniques, but rarely developing imagination, creativity, perceptual or spatial skills, essential requirements for a truly integrated design-based program. In this context, Gelernter (1988) made the case that this pedagogy: "implicitly assumes that the mind works in two quite distinct and sequential modes: first the mind is stocked with general knowledge of potentially universal application, then that knowledge is applied to practical problems. This treats the mind like some kind of simple filing cabinet [...]. The entire procedure is assumed to happen sequentially: first the folder is introduced, then filled and filed, then retrieved." Of course, educational literature has disproved this sequential approach to learning, and as Gelernter (1988) explains: "the two sides of knowledge acquisition and application must be attacked simultaneously."

Unfortunately, this discrepancy pertains not only to students, but also to their design tutors, who all too often have come through an educational system that has not versed them in an integrated (sustainable) design process, therefore reinforcing this divide. Further, those responsible for delivering the more technical and/or theoretical aspects of curricula are either rarely involved within the didactic studio process, are 'programmed' in such a way that they cannot converse in a manner 
that can meaningfully inform the design process, or are in such high demand that they cannot devote the time necessary to facilitate integration within the development of studio assignments.

Conversely, to promote a mature and 'deep' learning approach to design that includes, in a robust and rigorous manner, principles and practices of sustainability, students should be encouraged to engage in analytic and synthetic processes at a multitude of levels (Warburton, 2003).

A 'sustainable' curriculum should respond in a manner that emphasises reflection and critical peer/self-evaluation, where all parties take ownership of the challenges involved in balancing design creativity with environmental, socio-cultural and economic responsibility (Graham, 2002). In so doing, students should be exposed to more holistic aspects of sustainability, whilst developing a critical insight and awareness into those multidisciplinary problems that transcend sustainability issues. Ultimately, deep approaches to sustainability must be embraced by curricula, where sustainability is not just seen as a positive addition to the design outcome but, more importantly, as an essential requirement of the design process itself.

\section{Studio Culture and the Sustainability Challenge}

The challenges highlighted above reinforce the notion that conventional teaching and learning approaches may not be appropriate for addressing education for sustainability in the design studio. A fundamental restructuring of both the traditional studio culture and the modules within which core sustainability issues are taught is therefore worthy of consideration. In so doing, the priorities associated with sustainability should be shared widely - and embraced with commitment and enthusiasm - by all students and educators.

In order to recognise the potential pedagogical barriers that still hinder the achievement of such aims, EDUCATE performed a series of interviews with academics in more than 60 faculties and schools of the built environment from some 30 countries worldwide. Academics were presented with questions regarding sustainability in the academic curriculum and in pedagogical methods. 
Also, respondents were given the ability to reflect on the strengths and weaknesses of the educational structures in place within their own institution and contemplate whether sustainability is indeed integrated as a matter of 'course' or as a matter of 'force'. A critical analysis of the results obtained shows that, to effectively implement principles of sustainability in the pedagogies of architecture and urban design, educators felt the need to:

- Clearly define learning outcomes of academic programs and individual modules.

- Set qualitative and quantitative benchmarks and explicit criteria for assessment.

- Introduce problem-based learning in support of ex-cathedra delivery of information.

- Foster staff competence and familiarity with themes of sustainability.

- Encourage students to embark on reflection and peer/self-evaluation of their work.

- Promote the application of tools and techniques for exploration of solutions appropriate to the various stages of design development.

- Implement a balance between creativity and rigorous verification of proposed schemes.

- Support the engagement of staff and students with external experts starting from the early stages of development of briefs and throughout the design process.

- Develop integrated and inspiring delivery methodologies that support and reinforce dialogue, collaboration and team work within multidisciplinary studio staff teams.

- Reinforce emphasis on the ethical and socio-cultural values of sustainability.

To ensure that sustainability priorities are fully embraced in - and effectively inform - the process of design, the focus of academic programmes must be reconsidered, so as to foster deep learning and knowledge transfer, and bridge the divide between the often conflicting domains of lectures and studio. Such developments should provide graduates with meaningful technical knowledge and with the skills needed to creatively explore it within their design activities. Evidently, commitment, motivation and empowerment towards sustainability should inform all areas of the curriculum. Only by looking beyond the mere contents can successful learning outcomes be achieved. 


\section{Curriculum Development towards Education for Sustainability}

A framework for the development of a curriculum placing sustainability at the core of the education of architecture and urban design must be built on an overarching approach that comprehensively encompasses the learning outcomes of the programme, its pedagogical structure, the contents delivered, and the methods for teaching and learning (EDUCATE, 2011). The curriculum should, however, be primarily based on a 'mission agenda' - set up by the institution - where sustainability is seen as a priority in the education of students from the onset of their studies.

This should start from the design and operation of the institution itself and entail effective leadership in order for sustainability to be seen as a core theme by all students and staff (Graham and Geva, 2001). The advertisement of the course is also paramount, so as to attract enthusiastic staff and students, already with an understanding and/or a positive attitude towards the teaching and learning of sustainability. This requires that academic institutions are fully committed to this priority, providing much needed personnel, financial and time resources that, in conjunction with employing appropriate pedagogical methods, tools and techniques, will enthuse and inspire students to the needs for a sustainable approach to design. A successful education for sustainability must also be supported by appropriate regulatory frameworks set by legislative, prescription or accreditation bodies, to help foster investigative discourse between the various professions involved. An education that promotes sustainability needs to encourage students to be critically aware of, and reflect upon, the numerous interdependencies associated with the challenges at hand and, in so doing, contribute to the evolution of knowledge through exemplar research and responsible practice. To realize such aims, pedagogical developments must build on a critical analysis of the priorities expressed by the professional market, so as to respond to its practices and requirements. 


\section{Knowledge, Skills and Competence of Sustainable Design}

Sustainability has been widely acknowledged as a multidisciplinary domain that requires close collaboration between different disciplines. The learning outcomes that graduands should demonstrate at each level of their academic progression must reflect the skill set that is expected for the various subject areas that comprise the programme. When dealing with an integrated curriculum, such as where technical components are embedded within the ethos of design studio, learning outcomes become core. No longer can the outcomes for each module be seen in isolation, but they must be viewed, and delivered, as a comprehensive package.

To educate for sustainability, the acquisition of cognitive notions has to be combined with experiential and analytic abilities (AA, 2010). In other words, the attainment of knowledge must be reinforced through applied learning, where critical reflection helps synthesize or realise the task at hand. The theoretical knowledge that is necessary for translating (synthesizing) physical principles into design forms must be supported by empirical and evidence-based approaches to learning, thereby putting principles within the context of their practice. In so doing, students should develop a deeper awareness of the subject under exploration and indeed, from early stages in projects, should be able to appreciate the many interdependencies that contribute to the success of the task, and thus take an informed view of the likely outcomes of a project.

Appraisal of criteria that currently control graduate entry into built environment professions, however, reveals a substantial lack of clear and measurable indicators defining the level or type of knowledge, skills and competence of themes of sustainability demanded of students at each stage of their academic progression (EDUCATE, 2011). Whilst it is appreciated that such a lack of specificity is there to help embrace the diversity of a built environment education - and for that reason reflects local, national and international priorities - much could be gained by more informed and explicit guidance, thus preparing students for a professional landscape that itself demands sustainability as core to the design process as a whole. 
The terms knowledge, skills and competence here utilised derive from the European Qualifications Framework for Lifelong Learning (EQF), adopted by the European Commission to act as a "translation device to make qualifications more readable and understandable across different countries and systems" (EC, 2008). Although the classification of learning outcomes and the descriptors adopted do vary in nomenclature between educational frameworks, the achievements expressed by most of them remain comparatively similar. However, it is the discrepancy between what is achieved (according to these learning outcomes), where in the curricula they are achieved (at what stage in education), and how they relate specifically to the contents, credit or structure of specific programmes, that is important. This is a great challenge when reflecting on the relatively autonomous, independent and innovative nature of many programmes of higher education. Given their importance, EDUCATE explored these critically, reviewing pedagogies internationally, and resulting in the following recommendations (EDUCATE, 2011).

At undergraduate level, the first stage of higher education (e.g., Bachelors or undergraduate Masters, normally years 1 to $3 / 4$ of the curriculum), key values and principles of sustainability should be taught at an introductory level. By addressing a range of contemporary challenges that affect the building professions and the wider environment, the key outcomes are to increase awareness of sustainability issues, enthuse and motivate students into addressing these and, in so doing, seek commitment from students to respond to these issues in an appropriate manner. As such, knowledge itself becomes an empowering force and opens students up to the creative possibilities that flow from its exploration. To facilitate this process, students should be exposed to experiential learning aids that are at the disposal of educators, including appropriate case studies, field trips, laboratories, learning tools (e.g., mobile and computer applications), and so forth. Teaching and its associated learning must extend beyond those modules that are traditionally associated with sustainability, such as environmental design, architectural science, etc., and be embraced by the broader range of subjects within the programmes, including humanities, tectonics 
(e.g., structures and construction), etc. As such, sustainability should be informed not only by site, climate, typology, construction techniques and building occupancy, but also (and critically) by history, sociology, psychology and cultural studies, thus affording a rich setting through which traditional and contemporary design can be explored. Undergraduate students should be encouraged to be propositive, and the pedagogy should foster sensitivity towards the pragmatic and poetic creation of spaces. Knowledge of underlying regulatory frameworks should be introduced, helping students to gauge (or benchmark) their propositions against tangible qualifiable or quantifiable metrics. Whilst some may see such notions as being highly reductionist, this approach could afford students with the ability to ask better (or more relevant / appropriate) questions. Simple verification and calculation techniques should allow students to recognise constraints and explore solutions from early on in the design process and empower them to quickly explore the multi-faceted relationships with other built environment domains. Using such techniques, designs can be informed from the outset, the decisions that flow from these allowing students to explore proposed solutions in a more rigorous manner as the process evolves. This can only be realised, however, by supportive tutoring that steers a careful path between creative freedom and theoretical rigour (EDUCATE, 2011).

At graduate level, the second stage of higher education (e.g., Diploma or postgraduate Masters, years $4 / 5$ to $5 / 7$ of the curriculum), principles, strategies and solutions to sustainability issues should be explored in depth and linked strongly to multidisciplinary design. Students should be able to take a critical position in relation to the wider issues and objectives of sustainability and its expanding boundaries. Coursework should explore interconnected constraints of themes of environmental, socio-cultural and economic sustainability that can be creatively addressed. Students should be encouraged to develop autonomy in application, propose innovative solutions to questions and explore these using appropriate techniques. The role of design as an exploratory mechanism should be reinforced, stressing the importance of research by design and design by 
research. At graduate level, design must become a way of producing knowledge, exploring the complexity and interrelationships between complimentary and diverging views of the various actors of the built environment. Advanced design and verification tools, when introduced in direct connection with built case studies, provide an opportunity to foster data analysis and on-site observations, as well as engaging in comparative evaluation of performance data and calculated and/or simulated results. Knowledge and skills with respect to the regulatory frameworks and standards should be developed, including awareness of costs. Multidisciplinary and group work, preferably with an international dimension, should be encouraged to reflect market conditions and foster skills in interfacing with other professions (EDUCATE, 2011).

At the third stage of higher education, i.e. at postgraduate level (e.g., post-professional programmes), students should further deepen - and subsequently become more focused in - their interests, linking learning and application to development and research. At this stage, life-long learning becomes a priority, and students should be provided the opportunity to participate in activities that facilitate this, such as through Continuing Professional Development (CPD) initiatives or engagement in part-time further education. Abilities acquired should look comprehensively at the built environment in a holistic way. Students are expected to commit to cutting-edge scholarly and/or design research and demonstrate proficient direction in interacting with other professionalisms. They must be able to think critically about the nature of knowledge and how it is produced, expanded and validated, demonstrating competence in the performance targets of the built environment, from building, through urban design and landscape, up to consideration of wider environmental, economical, political and socio-cultural contexts. Advanced tools for analysis should be provided, so as to promote new avenues of research and the development of innovative design solutions (EDUCATE, 2011). 


\section{Programme Structure}

A plurality of structures could be adopted by academic programmes to accommodate the targeted learning outcomes (Guy and Moore, 2007). These, in fact, have to respond to the specific teaching culture, methodologies, resources (physical or manpower) and organisation of the higher education institution concerned.

In order to identify best practice in integrating sustainability in academic programmes and clarify strengths and opportunities of different pedagogical structures, EDUCATE has, through its exploration of academic curricula internationally, analysed the relationship between different disciplinary areas in several courses/degrees (EDUCATE, 2011), concentrating on: (1) content, that is the stages of education where specific information on sustainability is provided; (2) staff-tostudent ratio (SSR or full time equivalents, FTEs), for theoretical and applied modules; (3) delivery methods, e.g., specialist lectures, seminars, workshops, etc.; (4) pedagogical tools, including software, live projects, etc.; and, (5) assessment criteria, i.e. coursework, laboratory tests, fieldwork and so on. Based on the results of this analysis, a broad systematisation of five models in which academic programmes in architecture and urban design can be structured has been performed. These distinguish the various opportunities and constraints that each brings in affording the implementation of sustainability within an exploratory design discourse. Table 2 summarises diagrammatically these five programme structures (EDUCATE, 2011).

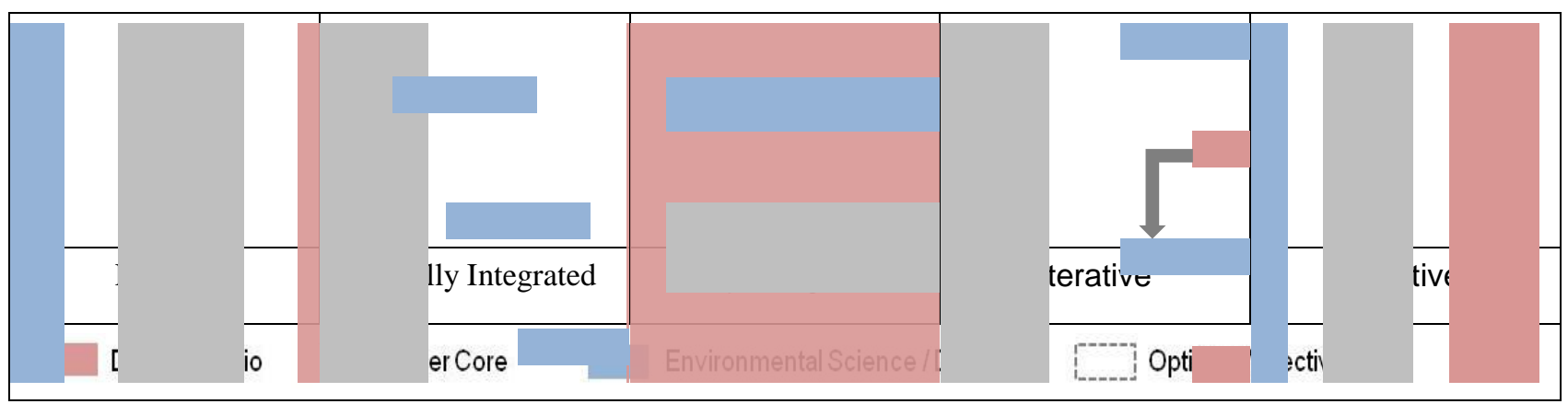

Table 2. Models of Programme Structure 
- Parallel: each disciplinary domain runs autonomously and knowledge is delivered basing on a 'satellite' approach, with dedicated lectures and stand-alone assessment. This structure can be highly efficient in terms of delivery and assessment and has the potential to foster a coherent and rigorous exploration of sustainability. Yet, such an approach may come at a price, where it is often seen as being divorced or remote from key design tasks. In other words, the autonomous nature of such an approach may not promote integration of sustainability within creative design.

- Partially integrated: different domains are linked in delivery or, more frequently, in assessment. Such an approach either sees the module itself bridging the disciplinary areas, or, in some cases, bridging modules are initiated that act as a forum for critical exploration of the work presented via more technical taught content. In the case of the latter, it may be that a particular sustainability-related theme as discussed within a lecture is explored in the bridging module through a case study. Whilst such an approach may demand significantly more resources than a parallel structure, it does bring with it the advantage that the rigorous exploration of the issues at hand can be assessed in a manner that judges the student's understanding of the specific domain. The bridging module itself can then seek to explore these issues at a more holistic level, as they apply to the design process. In other words, both rigour and its creative exploration may be embodied and, as such, promote deep learning through applied techniques. Assessment mechanisms are core to the success of the pedagogy.

- Fully integrated: various disciplines converge around the central core of the design studio (Levy, 1980). Principles and values of sustainability are delivered and assessed in connection with the requirements and development of the design project. This is one of the most contentious and difficult of all approaches, as it implies that design studio becomes the focus of all teaching and requires that sustainability be a core ethos of the curriculum. Its success is dictated not only by the content and assessment mechanisms employed, but by the skills, expertise, cooperation and 
motivation of the staff participating in the pedagogy. Hence, by assumption, all those teaching on the programme must also be passionate about, and committed to, sustainability.

- Iterative: knowledge is progressively deepened through a series of 'loops'. The curriculum does not follow a linear series of successive stages in knowledge delivery and assessment, but rather the complexity of the themes presented gradually grows throughout the course. Fundamental to the success of such a structure is that all modules, from those delivering technical or theoretical contents to those characterised by an exploratory and hands-on approach, must be built on clear interdependencies, where complexity of exploration increases with the programme.

- Elective: contents are enriched by optional courses, potentially structured as domain-specific teachings that students can include in their study program (e.g., Minors). The flexibility in the choice of the elective modules on offer - often from different faculties/departments - allows the exploration of sustainability (and/or other disciplinary domains) from various points of view. Whilst the elective approach is to a large extent costly in terms of both time and manpower, it does offer students the ability to explore an area that is of interest to them (EDUCATE, 2011).

Each structure offers potential opportunities and threats, hence it is necessary that the curriculum is supported by adequate pedagogical methods and tools that facilitate knowledge transfer between technical and applied domains (Salama, 2005). Indeed, process is essential for learning and the way in which learning occurs is as important as the content of the learning itself (Orr, 1991).

\section{Lectures and Studio as Places of Active Engagement}

In an education successfully embedding sustainability at the core of the curriculum, pedagogical strategies must provide the conceptual principles, empirical explorations, and analytic techniques necessary to inform design. By challenging traditional tansmissive pedagogies, it is possible to suggest that the objective of integrating the lecture and studio processes should be to encourage critical and creative thinking, problem solving, effective decision making and conflict resolution. 
Enquiry, discussion and applications should be fostered, so that connections between key concepts can be made and a framework that allows students to start on an evolutionary path of development can be provided (Schon, 1984). The learning environment must become one of cooperation and activity, treating students as active seekers of knowledge, engaged in lectures and design tasks (Rutherford and Wilson, 2006). Lectures should not be presented independently of studio. In fact, the contents presented at lectures will not be efficiently absorbed if the information is excessive, inaccessible, or not seen as consistent or relevant to the demands of the design project (Cole, 1980). In this context, a key technique that could prove successful to "foster unity between the learning process and the learner" (Auchey et al., 2000) is problem-based learning, whereas the motivation provided by the challenge supplies the incentive to learn (Smith, 2009). Problem-based learning can be successful not only in delivering knowledge, but also in training learners in a new way of thinking, providing the skills required to solve problems (Leroy et al., 2001) and preparing for lifelong learning (Grosskopf, 2004). When learners are given a problem and struggle to find the answer, they increase their interest levels in the subject, making the information acquired, as well as the thinking strategies involved, more memorable. On the other hand, when problem-based learning involves the application of knowledge to a practical task, students become engaged in the task and in the learning process itself, linking experience and observation to contextualisation and experimentation (Kolb and Kolb, 2005) and acquiring the ability to use effectively the knowledge gained. Engagement is one of the main processes to induce motivation, in that we learn more effectively when we are interested in the subject matter and we can combine theory and perceptual knowledge (Levy, 1980). Students who are motivated want to learn, are more interested in their task, and absorb knowledge more readily, triggering deep as opposed to surface learning (Filho, 2000). Both intrinsic (originating from a challenge) and extrinsic (caused by the ambition to achieve a reward) motivation can be activated by problem-based learning. Of the two, the intrinsic one (e.g., the experience) is probably the more valuable in terms of promoting life-long learning as 
it also involves a desire to understand (Lepper and Hodell, 1989). Conversely, a significant factor in supporting students' motivation towards learning can be represented by group support and peer influence on behaviour, again a form of extrinsic motivation (Child, 2004). Constructive feedback and student peer grouping can communicate and reinforce values, since the attitude and mentality of tutors and peers can influence the students' thinking (Smith, 2009).

In this context, to support collaborative learning and motivate participants through interactive exchanges, didactic tools deriving from Information and Communication Technologies (e.g., elearning) are presenting an opportunity to establish new ways for students to learn, work and collaborate with tutors and peers locally and globally, marking a significant step forward in combining creativity with practical skills. Obviously, the use of pedagogical e-learning tools should by no means be considered as a substitute for studio and lectures, although, by enabling some curricular activities to take place outside the physical boundaries of the studio, the effectiveness of a 'blended' pedagogy can benefit in increasing engagement of students (and staff), and as a result, enhancing the quality of the teaching and learning experience (Altomonte, 2010).

\section{Conclusions}

To facilitate the implementation of sustainability in architecture and urban design within a socioculturally, economically and creatively viable discourse, its principles and practices have to assume a central position within the formation of professional competence and ethos of practitioners from the earliest stages of education.

To this end, this paper has identified some of the key hindrances to the successful integration of sustainability in teaching and learning programmes and, consequently, has discussed some potential opportunities that could contribute to achieving such a target within higher education and in postprofessional training. 
With this in mind, research endeavours such as EDUCATE are a testament to the appreciation of the need to link more strongly the educational sector with parallel initiatives in the professional domain. Other ways forward may reside in linking continuous professional development for educators and practitioners directly to changing legislation, and benchmarking academic coursework against leading edge practice, using real case studies with proven performance credentials to help reinforce design methodologies.

In conclusion, education for sustainability must break out of traditional disciplinary compartments and bridge divides between technical rigour and creative exploration, research and application, technical sciences and creative arts, education at pre- and post-professional level.

Clearly, new forms of flexible and responsive teaching and learning should be transferred from other disciplines and challenge conventional pedagogical methods in architecture and urban design, since their implementation surely holds the potential to promote sustainability as the ultimate aim of any pedagogical process.

\section{Acknowledgements}

EDUCATE is funded by the European Agency for Competitiveness and Innovation (EACI) of the European Commission under the 'Intelligent Energy Europe' Programme 2008 (Contract n. IEE/08/635/SI2.528419). The authors heartily acknowledge the contributions given by all the EDUCATE partners to the results of the project to date and to the contents of this paper. A particular acknowledgement also goes to Ms Rebecca Smith who, in her MEng Dissertation "Guidelines for the Design of a 'Sustainable' Curriculum in Architecture and Architectural Engineering", investigated the challenges of sustainability in education, with particular reference to issues of ethos and motivation.

\section{References}

AA Architectural Association. 2010. MSc \& MArch Sustainable Environmental Design. http://www.aaschool.ac.uk/ee [2 November 2011]

Altomonte, S. 2009. Environmental Education for Sustainable Architecture. Review of European Studies 1(2):12-24.

Altomonte, S. 2010. Enhancing Teaching and Learning of Sustainable Design Through ICTs. ICETC International Conference on Education Technology and Computer, Shanghai.

Auchey, F.L., Kills, T.H., Beliveau, Y.J. and Auchey, G.J. 2000. Using the Learning Outcomes Template as an Effective Tool for Evaluation of the Undergraduate Building Construction Program. Journal of Construction Education 5(3): 244-259. 
Child, D. 2004. Psychology and the Teacher. London: Continuum.

Cole, R.J. 1980. Teaching Experiments Integrating Theory and Design. Journal of Architectural Education 34(2): 10-14.

EC-European Commission. 2008. The European Qualification Framework for Lifelong Learning $(E Q F)$. http://ec.europa.eu/education/pub/pdf/general/eqf/broch_en.pdf [8 January 2011]

EDUCATE, 2010a. State of the Art of Environmental Sustainability in Academic Curricula and Conditions for Registration. http://www.educate-sustainability.eu/state-of-the-art [3 November 2011]

EDUCATE, 2010b. State of the Art of Environmental Sustainability in Professional Practice. http://www.educate-sustainability.eu/state-of-the-art [3 November 2011]

EDUCATE. 2011. Framework for Curriculum Development. http://www.educatesustainability.eu/educate-framework.php [2 November 2011].

Clegg, P. et al. (2007). Feilden Clegg Bradley - The Environmental Handbook. London: Right Angle Publishing.

Filho, W.L. 2000. Dealing with Misconceptions on the Concept of Sustainability. International Journal of Sustainability in Higher Education, 1(1): 9-19.

Gelernter, M. 1988. Reconciling Lectures and Studios. Journal of Architectural Education 41(2): 46-52.

Graham, P. 2002. Building Ecology: First Principles for a Sustainable Built Environment. Wiley Blackwell.

Graham, C. W., Geva, A. 2001. Evaluation of an Interdisciplinary Studio Experience to Teach Architecture and Construction Science Students the Design-Build Project Delivery Method. Journal of Construction Education 6(2): 75- 90.

Grosskopf, K. R. 2004. Teaching Methods Improvement Using Industry Focus Groups: A Case Study in Construction Financing. International Journal of Construction Education and Research 1(1): 13-25.

Guy, S., Moore, S. 2007 Sustainable Architecture and the Pluralist Imagination. Journal of Architectural Education 60(4): 15-23.

HEA-Higher Education Academy. 2005. Sustainable Development in Higher Education: Current Practice and Future Developments. http://www.heacademy.ac.uk/resources [22 July 2011].

IPCC. 2007. Climate Change 2007. Fourth Assessment Report of the Intergovernmental Panel on Climate Change. Cambridge: Cambridge University Press.

Kincheloe, J.L. 2008. Knowledge and Critical Pedagogy: An Introduction. Springer.

Kirk, W.M., Mulligan, D. 1996. Teaching Right-Brain Thinking in a Construction Curriculum. Journal of Construction Education 1(1): 11-22.

Kock, A., Schwennsen, K., Dutton T.A., Smith, D. 2002. The Redesign of Studio Culture. A Report of the AIAS Studio Culture Force. Washington: AIAS-American Institute of Architecture Students.

Kolb, A. Y., Kolb D. A. 2005. Learning Styles and Learning Spaces: Enhancing Experiential Learning in Higher Education. Academy of Management Learning \& Education 4(2): 193-212.

Lepper, M. R., Hodell, M. 1989. Intrinsic Motivation in the Classroom. In Ames C., Ames R. Research in Motivation in Education. San Diego: Academic Press.

Leroy, P., van den Bosh, H., Ligthart, S. 2001. The Role of Problem Based Learning in the Political and Social Sciences of the Environment Curriculum at Nijmegen University. International Journal of Sustainability in Higher Education 2(1): 8-20.

Levy A. 1980. Total Studio. Journal of Architectural Education 34(2): 29-32.

Orr, D. 1991. What is Education For? The Learning Revolution 27.

Rutherford, P., Wilson, R. 2006. Educating environmental awareness: creativity in integrated environmental design teaching. In Shannon, S., Soebarto, V., Williamson, T., (Eds.) Challenges 
for architectural science in changing climates: Proceedings of the 40th annual conference of the Architectural Science Association ANZAScA. Adelaide: School of Architecture.

Salama, A. M. 2005. A Process Oriented Design Pedagogy: KFUPM Sophomore Studio. CEBE Transactions 2(2): 16-31.

Schon, D.A. 1984. The Architectural Studio as an Exemplar of Education for Reflection-in-Action. Journal of Architectural Education 38(1), 2-9.

Smith, R. 2009. Guidelines for the Design of a 'Sustainable' Curriculum in Architecture and Architectural Engineering. MEng Dissertation, University of Nottingham.

UNESCO. 2009. Review of Contexts and Structures for Education for Sustainable Development. http://www.unesco.org/en/education-for-sustainable-development/publications [8 December 2011]

Warburton, K. 2003. Deep Learning and Education for Sustainability. International Journal of Sustainability in Higher Education 4(1): 44-56. 